\title{
TRABALHO, CARREIRA E MATERNIDADE: PERSPECTIVAS E DILEMAS DE MUL- HERES PROFISSIONAIS CONTEMPORÂNEAS
}

WORK, CAREER AND MOTHERHOOD: THE OUTLOOKS AND DILEMMAS OF CONTEMPORARY WOMEN PROFESSIONALS

Recebido em: 21/05/2018 - Aprovado em: 16/08/2018 Avaliado pelo sistema double blind review Editor Científico: Edson Sadao Iizuka DOI 10.13058/raep.2018.v19n3.1119

\section{VIVIANE CORDEIRO DE ALMEIDA cmmotasantos@gmail.com CAROLINAMARIA MOTA-SANTOS}

Pontifícia Universidade Católica de Minas Gerais

\begin{abstract}
RESUMO
O caso apresenta a trajetória de vida e carreira da executiva Marrie Ometto e traça um panorama sobre as decisões em torno de questões como carreira e maternidade. Nesse caso, Marrie relembra o dilema vivido quando, após o nascimento da filha e, diante de vários conflitos interiores, ficou em dúvida se deveria abandonar a carreira. Os dados foram coletados por intermédio de duas entrevistas livres concedidas por Marrie às autoras. Outros dados que compõem a história foram encontrados não só no livro da protagonista bem como em seu blog. O caso é contado a partir do ponto de vista da personagem e propõe que os alunos analisem as decisões e dilemas enfrentados por mulheres profissionais contemporâneas para a manutenção de suas carreiras, ao mesmo tempo em que propõe uma reflexão a respeito dos desafios enfrentados por elas no que diz respeito à equação carreira, maternidade e qualificação profissional. O caso permite ainda formular as premissas necessárias para responder à seguinte pergunta: Por que o difícil balanço entre a vida pessoal e a carreira profissional encontra-se na raiz da insatisfação manifestada por uma grande parte de mulheres? Os resultados obtidos poderão ser discutidos em sala de aula com diversas pesquisas no campo de gestão de pessoas, os quais apontam que as mulheres se sentem mais felizes ao conseguirem equilibrar carreira e família. Palavras-chave: Caso de ensino, Carreira feminina, Maternidade, Tripla jornada, Mulheres contemporâneas.
\end{abstract}

\footnotetext{
ABSTRACT

The case presents the life and career trajectory of Marrie Ometto and outlines decisions surrounding the challenges revolving around career and motherhood. Marrie recalls her dilemma where, after the birth of her daughter and in the midst of various inner conflicts, she seriously considered abandoning her career. Data was collected through two free interviews conducted by the authors with Marrie. Other data that makes up the story came from her book and blog. The case is told from the point of view of the protagonist and proposes that students analyze the decisions and dilemmas faced by today's professional women in maintaining their careers, while proposing a reflection on the challenges faced by them as regards the equation made up by their profession, maternity and professional qualification. The case also offers the challenge of formulating the necessary premises to evaluate why the difficult balance between personal and professional life is at the root of the dissatisfaction expressed by a large number of women. The results obtained can be discussed in the classroom together with several studies in the field of people management that point to women feeling happier when they can balance their careers with their family lives.

Keywords: teaching case, women's career, maternity, triple day, contemporary women.
} 


\section{INTRODUÇÃO}

Em meados de 2017, a economista Marrie Ometto relembra o dilema vivido quando teve de fazer a difícil escolha de abandonar o cargo de executiva em uma grande empresa após o nascimento da filha. Após vários conflitos interiores e com o fim da licença-maternidade, Marrie ficou em dúvida se deveria abandonar a carreira, isto representava uma decisão árdua de ser tomada e elencou os fatores que influenciaram isso, desde a satisfação profissional, a contribuição para a renda familiar até o apoio do companheiro, entre outros. Após o nascimento da filha e inspirada pela nova realidade, Marrie criou o próprio blog Mamãe Plugada, no qual escreve para várias mulheres em situação semelhante, além de trocar experiências com as leitoras. Em um de seus posts, declara que, no Brasil, apesar de ter ocorrido algumas mudanças de peso, infelizmente, muitas empresas ainda consideram a maternidade como um ponto negativo para a carreira feminina. Em face disso, as mulheres que não possuem uma jornada de trabalho flexível enfrentam grandes desafios para dar conta de uma rotina tão intensa. Motivada pelas leitoras e por considerar que ter uma carreira profissional, estudar e ainda exercer a maternidade não é uma situação incomum, visto que grande parte das mulheres contemporâneas vive esta realidade, Marrie decidiu escrever um livro onde conta suas trajetórias pessoal e profissional. Ao compartilhar a história, a autora desejava ampliar a reflexão a respeito dos impasses das profissionais contemporâneas em relação às possibilidades de conseguirem êxito na equação carreira, maternidade e qualificação profissional.

Segundo a autora, uma das maiores pressões que as profissionais contemporâneas enfrentam atualmente não é apenas provar a competência profissional, mas, principalmente, conciliar as demandas da carreira com a vida pessoal. Portanto, percebia que assim como ela uma parcela significativa de profissionais se sente impelida a postergar a maternidade em virtude da carreira. Logo, a partir do dilema experimentado por Marrie e da realidade de muitas executivas se busca responder a seguinte pergunta: Por que o difícil balanço entre a vida pessoal e a carreira profissional encontra-se na raiz da insatisfação manifestada por uma grande parte de mulheres? 


\section{O LEGADO DOS PAIS E A TRAJETÓRIA DE VIDA PROFISSIONAL}

A economista piracicabana, Marrie Ometto de 35 anos, mãe de Clara de 4 anos, ao fazer uma retrospectiva da reviravolta gerada pela maternidade na vida pessoal e carreira profissional comenta com a mãe, Júlia, a dúvida vivenciada. Ao se recordar de alguns fatos, Marrie se espanta, pois anteriormente a maternidade, em princípio, demoraria, afinal não fazia parte de suas principais aspirações. A finalidade principal consistia em conseguir a tão sonhada realização profissional, mostrar suas competências e habilidades ao mundo corporativo. Os pais haviam-na preparado para ser uma pessoa independente e capaz de realizar o que se propusesse a fazer; cresceu ouvindo que deveria lutar por seus objetivos, por mais distantes que estivessem. Portanto, tinha sido criada para ser uma mulher determinada e dinâmica. Ela definitivamente não se via como uma mulher fraca ou alheia às suas próprias possibilidades de êxito no mundo acadêmico e corporativo. Já na sua infância tinha facilidade para aprender as coisas, era uma criança esperta e inteligente como todas costumam ser, com a diferença de que tinha infraestrutura que lhe permitia avançar em sua empreitada. Na visão da entrevistada, a partir da adolescência, os valores da base da educação que recebera teriam começado a ficar evidentes: "Você precisa ir além, não se contente com pouco, minha filha. Você pode muito mais que a mamãe. Você precisa olhar pra frente e vencer os desafios."

A fim de atender os desígnios traçados pela genitora, Marrie sabia que não haveria outro caminho a não ser o de muito esforço e dedicação, por isso, tornou-se uma jovem disciplinada para que atingir os alvos predeterminados: passar no vestibular e ingressar em uma boa universidade. Estudou com afinco tendo sido aprovada para o curso de Ciências Econômicas em excelentes faculdades tendo de escolher para onde iria. Escolheu USP, ${ }^{1}$ sonho de toda pessoa que pretendia ter uma carreira promissora, entrar nessa universidade já se constituía um passo imenso rumo ao sucesso pessoal e profissional. Marrie sentia que valera a pena as noites mal

1 Universidade de São Paulo é uma universidade pública mantida pelo governo do Estado de São Paulo. 
dormidas estudando, assim como os finais de semanas sem participar das festas junto aos amigos, enfim, sabia que cada esforço extra de fato tinha valido a pena!

Durante o curso, Marrie o esforço lhe proporcionou boas notas e muitos elogios de professores e colegas, pois realmente era uma estudante brilhante, além de curiosa e ambiciosa. Participava dos projetos de extensão, de pesquisas científicas, seminários, workshops e tudo mais que era oferecido. A cada disciplina procurava absorver o máximo, visto que tinha sempre em mente o alvo de ser um diferencial onde quer que fosse. Por causa de sua excelente trajetória na USP, conseguiu muitas ofertas de estágio em empresas de renome, por consequência, estagiou em boas empresas e, por meio disso, traçou os objetivos de carreira.

A conselho dos pais, Marrie aos 23 anos embarcou para Boston, Estados Unidos, para fazer um intercâmbio e, assim, adquirir fluência na língua inglesa. Após estadia de seis meses, Marrie dirigiu-se a Madri, Espanha, onde permaneceu por mais cinco meses e adquiriu fluência no espanhol. Nessa jornada, muitas coisas que lhe fizeram crescer como pessoa e profissional. Com a conclusão da faculdade, surgiu a oportunidade de trabalhar em uma grande empresa em São Paulo. No primeiro mês, no emprego, Marrie se destacou e conseguiu uma promoção que dobrou o salário. Essa façanha lhe rendeu tanto admiradores quanto concorrentes acirrados. Ao longo de sua trajetória profissional, Marrie trabalhou em empresas de bastante prestígio e visibilidade. Recebeu promoções e cresceu muito, obteve uma excelente remuneração que em um determinado momento chegou a ficar maior do que a do seu parceiro. Os planos de Marrie estavam a todo vapor e como uma mulher independente e ocupada, pensar na maternidade realmente não era algo que estivesse em sua agenda, pois estava determinada a construir uma sólida carreira. Marrie repetia para si mesma: "Vivemos em um mundo capitalista e a lógica é a produtividade, competências e resultados excelentes, não posso deixar nada me tirar o foco e atrapalhar meu caminho". Pensando assim, Marrie receava que alguma coisa lhe atrapalhasse, afinal lutara muito para chegar onde estava, sabia que aquela era a carreira com a qual havia sonhado e, por isso, investira tanto tempo e 
dinheiro em seu desenvolvimento pessoal e acadêmico. Além disto, Marrie conversava com as amigas e todas partilhavam da mesma opinião: "No início da profissão, a dedicação é mesmo maior. Quem nunca fez hora extra para terminar um projeto e impressionar o chefe? Faz parte, pois é um meio de provar sua capacidade para todos e até para si mesma. Ao mesmo tempo, esse comecinho também significa ter menos responsabilidades." 


\section{O CASAMENTO}

Aos 28 anos, na segunda semana do mês de maio, Marrie contraiu matrimônio, o noivo de 31 anos tinha formação em Engenharia Aeronáutica. $\mathrm{O}$ casal havia se conhecido durante o intercâmbio em Boston e desde então nunca se separaram. Dois jovens ambiciosos e com grandes sonhos. À medida que a carreira dos dois crescia, menos se encontravam. O casamento se mantinha, pois havia uma cumplicidade e um amor sem igual entre o casal. As rotinas de viagens do marido e a de executiva eram intensas. Viagens e reuniões constantes lotavam sua agenda, quase não sobrava tempo para a vida social e familiar. Marrie era movida a desafios e sua rotina profissional lhe proporcionava isto. Embora o marido adorasse isto em sua esposa e lhe desse apoio, sempre deixara claro que, em algum momento, gostaria de se tornar pai. Sempre que trazia o assunto à tona, Marrie se esquivava. 


\section{O DESPERTAR DO RELÓGIO BIOLÓGICO}

A maternidade era adiada em detrimento do sucesso e da ascensão profissional. No entanto, os pais de Marrie sempre que tinham a oportunidade alertavam-na sobre o relógio biológico da maternidade. Aos 30 anos, Marrie considerou ser o momento de engravidar, mas antes se questionou: "Tenho estabilidade no meu trabalho? Estou preparada financeiramente? Tenho alguém para dividir a responsabilidade de cuidar de um filho? Meu chefe é bacana e apoiaria minha decisão numa boa". Naquele momento, Marrie acreditava que para todas as perguntas as respostas eram afirmativas e, por isso, interrompeu o uso de contraceptivos e pouco depois engravidou. Apesar de feliz, sentiu-se assustada, não sabia como conciliaria maternidade e carreira. A profissão do marido exigia ausentar-se de casa durante muitos dias, residiam longe dos familiares, com os quais não poderiam contar nas tarefas do dia a dia. Além disso, Marrie sempre trabalhara muito, sempre extrapolava a carga horária e viajava constantemente, deixou para organizar estas questões quando Clara nascesse.

Ao noticiar, em êxtase, a gravidez para a equipe de trabalho, Marrie percebeu que as pessoas começaram a olhá-la de uma forma diferente. Em suas palavras: "O mundo corporativo é muito cruel, principalmente o mercado financeiro (área em que atuava) e quando receberam a notícia de minha gravidez, não fugiu nenhum um pouco à regra." Naquele momento, ela levou um baque, visto não ter se sentido apoiada, pelo contrário. Havia valorizado demais todo o caminho percorrido para estar ali, mas começou a perder a vontade de continuar trabalhando. Dessa maneira, os conflitos internos cresciam gradativamente. 


\section{A MATERNIDADE E O DILEMA}

A decisão de parar temporariamente de trabalhar para cuidar da filha era um pensamento permanente, no entanto, amedrontador. Com o término da licença maternidade, Marrie retornou o trabalho e, para isso, matriculou a filha em uma excelente escola em período integral. No início, para que a filha se ambientasse bem, Marrie teve de ficar durante uma semana acompanhando o período de adaptação. Com passar do tempo, Marrie percebeu que aquela situação começou a lhe incomodar muito. Ela trabalhava uma jornada de 44 horas semanais e, como morava em São Paulo, gastava no mínimo uma hora de desloacamento para ir e voltar e mal conseguia ficar com a pequena Clara. Por consequência, a menina passava a maior parte do tempo na escola.

Marrie corria para dar conta de todas as tarefas, uma agenda intensa, algumas viagens, os cursos para se atualizar. Diante disso, precisava se organizar bastante para conciliar a rotina de trabalho e da maternidade. Apesar da ajuda da babá e de uma funcionária que cuidava da casa, sua rotina tornava-se cada vez mais conturbada. Resolveu ter uma conversa com o marido: "Eu desejo participar ativamente da criação de nossa filha, o que requer tempo disponível, e tempo ultimamente é um fator escasso em minha rotina. Eu gostaria de acompanhar as conquistas de cada fase, principalmente nos primeiros anos de vida de Clara. Cuidar, dar atenção, afeto, ou seja, auxiliar no desenvolvimento emocional e físico". Embora o marido tivesse ficado surpreso, pois jamais imaginara ouvir isto. Marrie continuou: "Se eu tivesse um emprego que fosse mais flexível, que eu mesma pudesse fazer meus horários e montar minha agenda de acordo com minha atual realidade, tudo seria mais fácil. Mas você sabe que hoje isto não será possível. Eu definitivamente preciso fazer esta escolha agora!” Após uma longa conversa, o casal fez as contas e refletiu sobre o que considerava como prós e contras e, finalmente, decidiram pelo afastamento do trabalho. Temporariamente, a carreira escolhida teria de ficar para depois. Embora Marrie tenha sentido uma avalanche de sentimentos que a deixou bastante reflexiva, não hesitou: "Tenho certeza de que estou fazendo a me- 
lhor escolha e em nenhum momento devo me sentir envergonhada por isto!" Apesar de Marrie sentir falta do ambiente de trabalho, pois se sentia valorizada profissionalmente, sentia falta também de ter o próprio salário e da independência financeira. Segundo ela, "Na minha vida inteira, principalmente quando estava estudando, eu não imaginava que iria enfrentar esse dilema." Contudo, consolava-lhe saber que tinha o privilégio de acompanhar de perto o crescimento e desenvolvimento de sua filha, trazia-lhe alívio o fato de que podia ter no parceiro um alicerce para este momento. Muitas pessoas criticavam-lhe a decisão; algumas amigas do trabalho insistiam em afirmar que ela estava se anulando, abrindo mão dos seus planos profissionais. No entanto, Marrie pensava: "Sou focada e sei que, no momento certo, vou arrumar um emprego em um local que permita que eu concilie o meu papel de mãe com o de profissional, que entenda que eu posso sair no meio do expediente para levar a minha filha ao pediatra porque eu produzirei excelentes resultados em outro momento".

Atualmente, Marrie sente-se plena e realizada com a família que construiu e é feliz pela decisão tomada de acompanhar e estar perto da filha durante a primeira infância. Ainda assim, Marrie continua a ser uma mulher destemida, de alma independente que acredita e corre atrás dos sonhos, embora ainda carregue consigo um grande dilema: "Será que é possível ter êxito na equação carreira e maternidade?" 


\section{O MUNDO CORPORATIVO}

$\mathrm{Na}$ visão de Marrie, o mundo corporativo é ainda muito cruel com a mulher que se torna mãe tendo em vista serem escassas as empresas que propiciem às mulheres equilibrarem carreira e maternidade, sobretudo, para aquelas que querem ter um envolvimento intenso com a maternidade. A situação ainda foi pior devido ao fato de pertencer a uma área muito agressiva, pois trabalhava com fusões e aquisições, análise de investimento, planejamento estratégico, além de ocupar um cargo de confiança. Conforme seu depoimento: "Você precisa estar lá na hora que precisa estar. Imagina, você vai comprar uma empresa agora... Ah, meu filho tem pediatra. Eles não querem nem saber. Temos de fechar a negociação, nós não vamos perder milhões." Além disso, Marrie relata que o universo masculino também dificulta o equilíbrio para a mulher. Escolheu essa área por ser a de que mais gostava, porque se considera muito ativa e não tinha muita rotina, pois cada hora analisava um projeto, completa: "Eu adorava isso, amava e nunca pensei que essa falta de rotina seria muito ruim para mim na hora que eu precisasse de rotina. Eu fui pensar nisso depois de grávida."

Marrie adorava o trabalho que exercia e se angustiou muito ao enfrentar o impasse de não conseguir equilibrar suas demandas. Após a maternidade, refletiu se deveria ter optado por uma trajetória de carreira mais simples do a que construiu. Por vezes, pensava que deveria ter optado por áreas diferentes da que atuava. Sob essa ótica, questionava se deveria ter feito escolhas diferentes, para não ter de enfrentar os desafios atuais: "Minha nossa, mas como vou fazer agora? Talvez se eu tivesse escolhido uma carreira mais tranquila, né? Porque tem áreas mais tranquilas nas empresas." Ao mesmo tempo sabia que não deveria se culpar pelas mudanças de rotina ocorridas em sua vida, uma vez que faziam parte do curso natural da mulher profissional ao optar pela maternidade. Diante do exposto, passou a acreditar que a responsabilidade de discutir e promover políticas de gestão de pessoas, que não excluísse esta realidade da trajetória das carreiras femininas, deveria ser das organizações. 
Assim que engravidou Marrie obervou as mudanças em relação ao trabalho como, por exemplo, o comportamento das pessoas com ela e depois do nascimento piorou bastante. Como a empresa para qual ela trabalhava era uma multinacional norte-americana, a cultura de licença maternidade é diferente da brasileira. A gestora de Marrie era estadunidense e havia ganhado bebê poucos meses antes dela e não chegou a ficar dois meses de licença. Ela chegou a receber ligação da gestora quando o bebê dela era recém-nascido e cobrava de Marrie produtividade, afirmava que o cargo exercido era de confiança e deveria dar exemplo. Certa vez, a gestora chegou a dizer: "Olha, Marrie, você não é um peão qualquer aqui, você precisa se atentar para isto."

Marrie, ao receber estes avisos, sentia a pressão para que as questões referentes à sua gestação não interferissem de nenhum modo na sua produtividade na empresa. Sabia que uma hora ou outra não suportaria mais tamanha pressão. Pouco tempo depois, Marrie decidiu-se por se desligar da empresa, procurou por seus superiores e propôs um acordo, que aceito lhe trouxe alívio. Ao se desligar da empresa, acreditava não ser difícil encontrar outras organizações que fossem mais flexíveis com as demandas de profissionais mães. De fato não foi muito complicado encontrá-las, no entanto, ao entrar em contato com algumas destas, inclusive algumas de renome no mercado nacional e internacional, ficou absolutamente frustrada com a realidade que conheceu.

Embora estas empresas sejam mais inclusivas para profissionais mães, o salário elas oferecido era muito aquém do vivenciado no mercado por mulheres profissionais não mães. Algumas destas empresas ofereciam, por exemplo, escola dentro da própria empresa, entretanto, com um salário quase pela metade do que era praticado e sem bônus. Uma realidade, portanto, inadequada. Desta maneira, Marrie se sentia cada vez mais sem esperanças em conseguir uma empresa que a valorizasse financeiramente e lhe proporcionasse a oportunidade de conciliar as demandas pessoal e profissionais. Percebeu que tal façanha certamente seria improvável de ocorrer no ambiente ao qual estava habituada a trabalhar, ou seja, no mercado de aquisições, fusões e no mercado financeiro em geral. Para ela este era um 
ambiente de pouca flexibilidade e ainda se atribuía certa dose de descrédito ao trabalho feminino.

No entanto, Marrie desejava voltar à ativa, apesar de estar feliz de exercer a maternidade, o trabalho ocupava um espaço muito especial em sua vida. Lagar sua carreira profissional definitivamente não fazia parte de objetivo, pois ainda poderia ser muito produtiva e criativa. Após o nascimento da filha, notou que adquirira novas habilidades e, por isso, passou a acreditar que a maternidade havia lhe instrumentalizado ainda mais para as vivências do mercado de trabalho.

Sem encontrar empresas que lhe ajudasse a superar os dilemas mais facilmente, Marrie fez uma pausa na sua carreira e se entregou ao exercício das funções maternas. De acordo com Marrie, as demandas de cuidado eram intensas e exaustivas, mas apaixonantes, pois estar com a pequena Clara era sempre um misto de emoções, ora prazer intenso, ora frustração e inquietude. Marrie considera que a pausa na carreira serviu como um momento de grandes reflexões e crescimento pessoal, mas antes de chegar a autodescoberta enfrentou "o ápice da ausência de si". Marrie sentia que havia se perdido, até mesmo desaparecido. Incialmente, pensava que aquela mulher autônoma e determinada nunca mais teria lugar de protagonista em sua história, ela não compreendia o porquê de se sentir assem, afinal, amava a filha e estava feliz por estar com ela. No decorrer do tempo, Marrie percebeu a falta do trabalho e de exercer suas habilidades profissionais. Na medida em que Marrie foi se conhecendo, surgiu novamente o desejo de fazer algo além das demandas pessoais que lhe trouxesse prazer e a fizesse se sentir viva profissionalmente de novo. 


\section{PERCEPÇÃO DOS SINAIS PARA VOLTAR AO MERCADO DE TRABALHO}

Quando Marrie começou a perceber que estava ficando ociosa e a vontade de se sentir produtiva não lhe saía da cabeça, lembrou-se de um blog que havia criado um tempo atrás porque, de vez em quando, gostava de escrever como hobby. Os assuntos em pauta geralmente eram sobre as tendências do mercado da moda, os pantones de cores da estação, enfim, tudo que estivesse lhe aguçando os sentidos num dado momento.

Quando Marrie engravidou, começou a pesquisar sobre enxovais de bebês, custo benefícios de comprar no Brasil ou nos Estados Unidos. Desta maneira, intuitivamente, começou a escrever acerca de gestação, filhos e outros assuntos relacionados à maternidade e investir mais tempo no blog. Como o assunto de sua vida no momento girava em torno da maternidade e da frustração em relação à última empresa estava presente, posts com as temáticas abandono de carreira pós-maternidade, insatisfação com empresas inflexíveis, fusão mãe e mulher, desapareci quando virei mãe... surgiram de forma espontânea. Os textos eram lidos por mulheres que, assim como ela, viviam esta realidade.

Em seus comentários, as leitoras sem jornada de trabalho flexível salientavam que precisam ser verdadeiras equilibristas para dar conta de uma rotina tão intensa. O sucesso do blog fez Marrie aumentar a participação nas redes sociais e começar a discutir esses assuntos com as leitoras. Logo, os acessos ao blog cresceram e Marrie entendeu que era hora de transformá-lo em negócio. O que antes tinha sido um mero hobby começou a tomar corpo e, por isso, contratou uma consultoria para ajudá-la a desenvolvê-lo profissionalmente. Assim, contratou uma consultoria de branding para criar uma marca e alavancar o negócio. Esta consultoria trouxe várias contribuições relevantes, dentre elas, a divulgação da própria marca e a criação de produtos e serviços. 


\section{MOTA SANTOS}

Figura 1 Livro publicado pela protagonista do caso
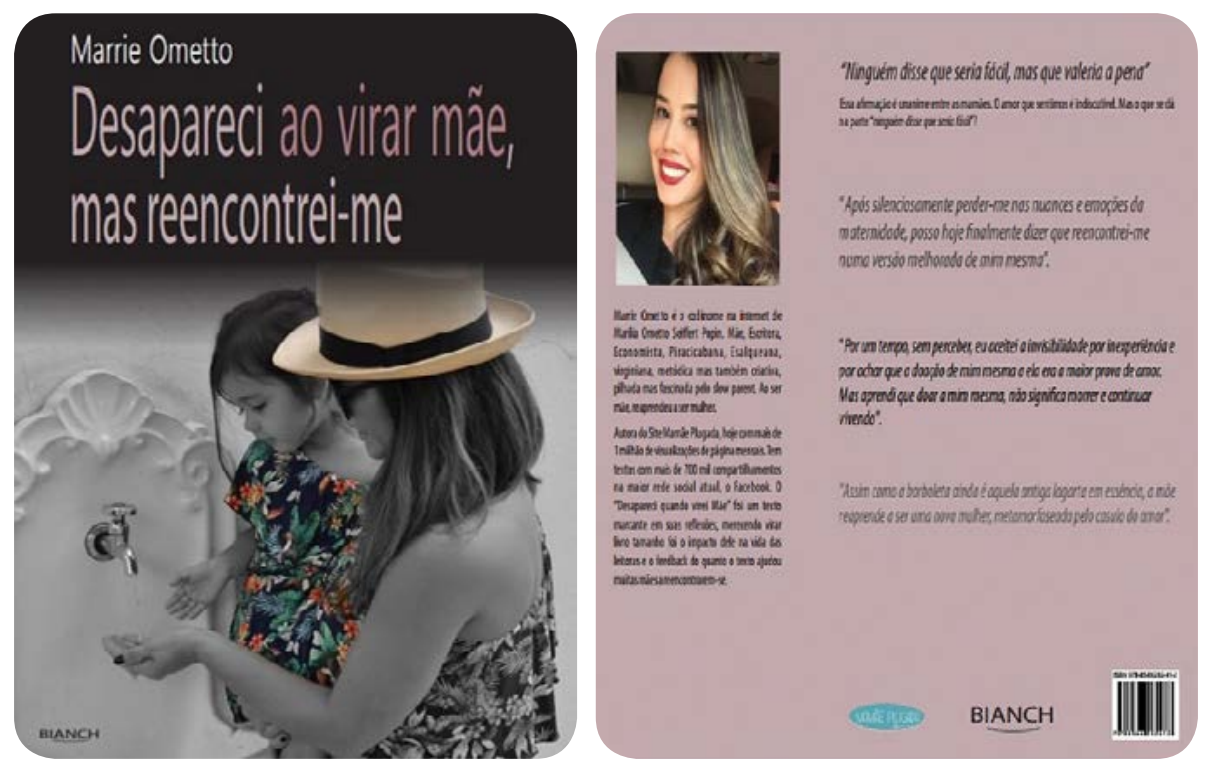

Fonte: Extraído de http:/ / marrieometto.com.br/

Desse modo, surgiu o nome Mamãe Plugada e a repercussão cresceu exponencialmente e, por conseguinte, tornou-se uma empresa bem rentável. A cada novo texto postado havia um retorno quase imediato do público, fazendo com que Marrie sentisse o desejo de compartilhar tanto os dilemas quanto a superação vivenciada. Em face disso, sentiu-se motivada e percebeu que havia se reencontrado. Uma vez tendo sido motivada a compartilhar sua história e a refletir sobre tais dilemas, várias ideias surgiram que culminaram em um livro, conforme apresentado na Figura 1.

O sucesso conta atualmente com mais de um milhão de visualizações mensais em seu blog Mamãe Plugada, cuja história é compartilhada com várias mulheres, mães e profissionais, que enfrentam os desafios das demandas da vida pessoal e profissional. Deste modo, surge-nos à pergunta: quais as contribuições não só para as profissionais, bem como para as organizações poderiam surgir ao se repensar o dilema vivenciado por Marrie? 


\section{AS FONTES E OS MÉTODOS DE COLETA DE DADOS}

Os dados foram coletados por meio de duas entrevistas livres concedidas pela protagonista do caso a autora que concedeu autorização para publicá-lo. Outros dados que compõem a história foram encontrados no livro escrito por Marrie Ometto intitulado: Desapareci ao virar mãe, mas reencontrei-me (Anexo A) e em seu blog Mamãe Plugada. Marrie Ometto é o codinome na internet da escritora e economista, natural de Piracicaba,Marilia Ometto Seiffert Popin. ${ }^{2}$

2 OMETO, M. Blog: Mamãe Plugada. Disponível em: <https:/ / www.mamaeplugada.com.br/era-uma-vez-uma-menina-tinhosa-21385>. Acesso em: 13 jan. 2018, OMETTO, M. Desapareci ao virar mãe, mas reencontrei-me. São Paulo: Bianch Pilot Training, 2017. 


\section{NOTAS DE ENSINO}

\section{OBJETIVOS DE ENSINO}

Desenvolver a capacidade de analisar as mudanças ocorridas no mercado de trabalho, no que diz respeito à maternidade, à vida pessoal e a sua relação com a carreira das profissionais contemporâneas. Discutir estratégias para que as profissionais possam lidar com os dilemas e conflitos relacionados a estas questões. Por fim, capacitar os alunos para avaliarem e/ou elaborarem programas nas áreas de Gestão de Pessoas que discutam os conflitos das profissionais contemporâneas em relação à tripla jornada de trabalho.

\section{RELAÇÕES COM OS OBJETIVOS DE UM CURSO OU DISCIPLINA}

É possível identificar aspectos relacionados ao desenvolvimento que englobam a construção de uma carreira feminina e os desafios de equilibra tanto a vida profissional quanto a pessoal. Esse caso é sugerido para fomentar discussões reflexivas na graduação e nos cursos de pós-graduação, sobretudo, aqueles direcionados à Gestão de Pessoas. Além disso, poderá ser utilizado para trabalhar com grupos de estudos que pretendem compreender um pouco mais a respeito dos dilemas enfrentados pelas mulheres profissionais quando o assunto é maternidade e carreira. Os alunos poderão ser instigados a debaterem acerca das diferentes percepções quanto à tripla jornada de trabalho feminina: carreira, maternidade e qualificação profissional. Neste sentido, poderão ser abordadas também as temáticas: equilíbrio entre carreira e vida pessoal; teto de vidro (glass ceiling) e Gênero nas organizações; divisão sexual do trabalho; e políticas de RH para gestantes e pós-gestantes.

\section{DISCIPLINAS SUGERIDAS PARA USO DO CASO}

$\mathrm{Na}$ área de Gestão de Pessoas: carreira feminina; trabalho e gênero; qualidade de vida no trabalho.

\section{PREPARAÇÃO PARA O CASO}

É importante a leitura do caso realizada pelos alunos antes da aula presencial e a leitura de alguns artigos a fim de fornecer subsídios à discussão, 
principalmente em relação à terminologia muito usada na Administração para abrodar as barreiras experimentadas por muitas mulheres para crescer profissionalmente: glass ceiling. Uma vez em sala de aula, o objetivo é suscitar o aprofundamento e uma discussão crítica do assunto, o professor poderá trabalhar com equipes de cerca de quatro alunos estipulando a previsão de término da tarefa em quarenta minutos. Podem ser trabalhadas, no primeiro momento, as primeiras questões relacionadas ao item 1.0.

Para o aprofundamento e a fixação dos conceitos, sugere-se a realização de uma plenária, estima-se que trinta minutos seja suficiente para as discussões. Nessa fase, é oportuno que tanto o professor quanto os alunos façam o registro dos elementos mais relevantes do caso e da base teórica que sustenta a discussão, tais como: carreira feminina, crescimento profissional versus pessoal, entre outros. Em uma última etapa, é recomendável que as questões complementares sejam realizadas em casa e individualmente para que, na aula seguinte, aconteçam as discussões finais a fim de sanarem as possíveis dúvidas. É importante também sugerir nesse momento, autores para que, posteriormente, os alunos aprofundem mais a temática.

\section{AULA I - QUESTÕES PARA DISCUSSÃO INICIAL}

1. Faça a leitura do caso tentando identificar os desafios vividos pela profissional protagonista. Em seguida, discuta com seu grupo as dificuldades relacionadas dedicação à vida pessoal (família, demandas da casa), à vida profissional e à qualificação, a partir das perguntas.

1.1. Faça uma breve análise das mudanças ocorridas na sociedade em relação à participação feminina no mercado de trabalho.

1.2. Os aspectos relacionados ao sistema patriarcal influenciam a vida da mulher contemporânea?

1.3. Quais os impactos dos movimentos feministas na vida da mulher contemporânea?

1.4. O que significa a terminologia glass ceiling (teto de vidro) e qual o impacto disso na carreira das mulheres? 
1.5. Relacione o conceito da tripla jornada de trabalho aos possíveis impactos na vida pessoal e profissional das mulheres contemporâneas.

1.6. As escolhas entre carreira, crescimento profissional e maternidade mostram-se um caminho fácil de ser percorrido? Por quê?

1.7. Quais os impactos na carreira das mulheres diante de uma possibilidade de jornada flexível?

1.8. O legado dos pais pode influenciar a escolha profissional e pessoal das mulheres? Se sim, explique essa situação.

1.9. Quais os possíveis apoios que as mulheres executivas que querem vivenciar a maternidade podem recorrer?

1.10. Quais aspectos precisam ser discutidos na vida da mulher que busca ter uma carreira de sucesso e deseja a maternidade?

1.11. Quais aspectos precisam ser discutidos na vida da mulher com uma carreira de sucesso, mas diante da maternidade se vê diante de um grande dilema (no sentido de deixar o trabalho temporariamente)?

1.12. O empreendedorismo pode ser uma boa opção? Se sim, explique o porquê.

\section{AULA I - QUESTÕES PARA O APROFUNDAMENTO CONCEITUAL}

O caso de Marrie Ometto aborda reflexões quanto ao número crescente de mulheres que abandonam a carreira quando nascem os filhos. Por meio da análise do caso surgem possibilidades de repensar como as organizações lidam atualmente com a questão da maternidade, fato bastante relevante para a sociedade contemporânea. Deste modo, pede-se que na primeira etapa discuta e apresente por escrito as respostas relativas às indagações apresentadas a seguir:

a. Seria possível criar políticas públicas e de recursos humanos em que se contemplasse maior flexibilização da jornada de trabalho para mães sem prejuízo para a organização? 
b. É possível conseguir êxito na equação carreira e maternidade? Como as organizações podem ajudar neste processo?

c. O adiamento da maternidade tem sido visto como um caminho para se conseguir pleno sucesso na carreira profissional?

Segunda etapa - plenária

a. Discuta com os demais grupos as respostas encontradas pelos demais pequenos grupos. Registre os elementos mais importantes do caso e a base teórica que sustenta a discussão.

b. Juntamente com seu grupo pequeno, proponha duas estratégias a partir do que foi discutido com o grupo maior para que as profissionais possam lidar com os dilemas e conflitos que perpassam os temas: carreira; maternidade e qualificação profissional.

\section{AULA II - QUESTÕES COMPLEMENTARES}

2. - Planejar é sempre bom para a carreira feminina? Ou quando se fala em maternidade, isso não é viável?

1. O que você faria semelhante se estivesse no lugar da executiva Marrie Ometto?

2. O que você faria diferente?

3. Qual o impacto na vida profissional que a decisão de sair do emprego pode gerar no futuro profissional?

4. Qual o impacto na vida pessoal que a decisão de sair do emprego pode gerar na vida dessa executiva?

5. Como o profissional de Gestão de Pessoas poderia criar programas para que as profissionais que desejam ter filhos se sintam confortáveis e seguras para fazê-lo? 


\section{REFERÊNCIAS SUGERIDAS}

ADLER, N. J.; BRODY, L. W.; OSLAND, J. S. The women's global leadership forum: Enhancing one company's global leadership capability. Human resource management, v. 39 , n. $2,-3$, p. $209-225,2000$.

ANDRADE, J. O. et al. O contexto do trabalho na visão de mulheres profissionais brasileiras. In: EnAnpad, 37., 2013. Rio de Janeiro, Anpad. Anais... Rio de Janeiro: Anpad, 2013.

ANDRADE, J. O. et al. Maternidade: novas possibilidades, antigas visões. Psicologia Clínica, Rio de Janeiro, v. 19, n. 1, p. 163-185, 2007.

BARBOSA, P. Z.; ROCHA-COUTINHO, M. L. Ser Mulher Hoje: A visão de mulheres que não desejam ter filhos. Psicologia \& Sociedade, Rio de Janeiro, v. 24, n. 3, p. 577-587, 2012.

BELTRAME, G. R.; DONELLI, T. M. S. Maternidade e carreira: desafios frente à conciliação de papéis. Aletheia, n. 38-39, p. 206-217, 2012 .

BERTOLINI, L. B. A. Relações entre o trabalho da mulher e a dinâmica familiar. São Paulo: Vetor, 2002.

BRUSCHINI , C.; PUPPIN , A. B. O trabalho das mulheres executivas no Brasil no final dos anos 20. Cadernos de Pesquisa, v. 34, n. 121, p. 105-138, 2004.

CARVALHO NETO, A. M.; TANURE, B.; ANDRADE, J. Executivas: Carreira, Maternidade, Amores e Preconceitos. RAE - eletrônica, v. 9, n. 1, jan.-jun. 2010.

CERIBELI, H. B.; SOUZA ROCHA, G. B.; PEREIRA, M. R. Mulheres em cargos de chefia: desafios e percepções. Diálogo, n. 36, p. 9-24, 2017.

CORRÊA OLIVEIRA, S. et al. Maternidade e trabalho: Uma revisão da literatura. Interamerican Journal of Psychology, v. 45, n. 2, 2011.

DESSEN, M. A; BRAZ, M. P. Rede social de apoio durante transições familiares decorrentes do nascimento de filhos. Psic.: Teoria e Pesquisa, v. 16, n. 3, p. 221-231, 2000.

ENGEN, M. L.; LEEDEN, R.; WILLEMSEN, T. M. Gender, context and leadership styles: A field study. Journal of occupational and organizational psychology, v. 74, n. 5, p. 581-598, 2001.

EKLUND, K. E.; BARRY, E. S.; GRUNBERG, N. E. Gender and leadership. Gender Differences in Different Contexts. Cidade: InTech, 2017.

FIORIN, P. C.; OLIVEIRA, C. T.; DIAS, A. C. G. Percepções de mulheres sobre a relação entre trabalho e maternidade. Revista Brasileira de Orientação Profissional, v. 15, n. 1, p. 25-35, 2014.

GOMES, A. G. et al. Maternidade em idade avançada: aspectos teóricos e empíricos. Interação em Psicologia, v. 2, n. 1, p. 99-106, 2008. 
GREENHAUS, J. H.; PARASURAMAN, S.; COLLINS, K. M. Career involvement and family involvement as moderators of relationships between work-family conflict and withdrawal from a profession. Journal of occupational health psychology, v. 6, n. 2, p. 91-100, 2001.

GROSSI, M. P.; SCHENDEILWEIN, I. L.; MASSA, J. M. Discriminação tem gênero no Brasil. GV-executivo, v. 12, n. 1, p. 37-41, 2013.

HENRY, C. et al. Entrepreneurial leadership and gender: Exploring theory and practice in global contexts. Journal of Small Business Management, v. 53, n. 3, p. 581-586, 2015.

HURLEY, A. E. Incorporating feminist theories into sociological theories of entrepreneurship. Women in management review, v. 14, n. 2, p. 54-62, 1999.

KLENKE, K. Women in Leadership 2nd Edition: Contextual Dynamics and Boundaries. Cidade: Emerald Publishing Limited, 2017.

LIMA, G. S. et al. O teto de vidro das executivas brasileiras. Revista Pretexto, v. 14, n. 4, p. $65-80,2018$.

LOUREIRO, C. M. P. et al. Trajetórias profissionais de mulheres executivas: qual o preço do sucesso? Revista de Ciências da Administração, v. 14, n. 33, p. 130-144, 2012.

LOPES, M. M. "Aventureiras” nas ciências: refletindo sobre gênero e história das ciências naturais no Brasil. Cadernos Pagu, v. 10, p. 345-368, 1998.

MARTINS, L. L.; EDDLESTON, K. A.; VEIGA, J. F. Moderators of the relationship between work-family conflict and career satisfaction. Academy of Management Journal, v. 45, n. 2, p. 399-409, 2002.

MOTA-SANTOS, C. M.; TANURE, B.; CARVALHO NETO, A. As mulheres executivas brasileiras: o teto de vidro em questão. RAD, v. 16, n. 3, p. 56-75, 2014.

MOTA-SANTOS, C. M. et al. As mulheres estão quebrando as três paredes de vidro? Um estudo com empreendedoras mineiras. E\& G-Economia e Gestão, v.16, n.45, p. 126-149, Out/Dez, 2016.

MOTA-SANTOS, C. M.; CARVALO NETO, A. O papel da família na trajetória profissional de mulheres executivas e empreendedoras. Revista Alcance - eletrônica, v. 24, n. 1, p. 36-49, 2017.

POWELL, G. N.; GREENHAUS, J. H. When family considerations influence work decisions: Decision-making processes. Journal of Vocational Behavior, v. 81, n. 3, p. 322-329, 2012.

RIOS-LIMA, M. G. Um estudo sobre o adiamento da maternidade em mulheres contemporâneas. 2012. 200f. Tese de Doutorado pelo Instituto de Psicologia, Universidade de São Paulo, São Paulo, 2012.

RODRIGUES, C.; SAPUCAIA, M. Proteção à maternidade: uma reflexão sobre apaziguamento e sedimentação das desigualdades entre homens e mulheres. Revista da ABET, v. 15, n. 1, p. 22-32, 2016. 


\section{MOTA SANTOS}

SANTOS, C. M. M. As mulheres brasileiras: do espaço privado da casa para as posições executivas nas organizações brasileiras. 2012. Tese (Doutorado) - Unidade, Pontifícia Universidade Católica de Minas Gerais, Belo Horizonte. 2012.

SANTOS COUTINHO, S. M.; MENANDRO, P. R. M. Representações sociais do ser mulher no contexto familiar: um estudo intergeracional. Psicologia e Saber Social, v. 4, n. 1, p. 52-71, 2015.

SCAVONE, L. Maternidade: transformações na família e nas relações de gênero. Interface, Comunicação, Saúde, Educação, v. 5, n. 8, p. 47-60, 2001.

SCHEIN, V. E. Women in management: reflections and projections. Women in management review, v. 22, n. 1, p. 6-18, 2007.

SILVA, J. C.; DAL MAGRO, C. B.; SILVA, M. Z. Gender inequality in accounting profession from the perspective of the glass ceiling. RACE-Revista de Administração, Contabilidade e Economia, v. 15, n. 2, p. 447-474, 2016.

SOUZA, F. M.; BERNARDES VOESE, S.; ABBAS, K. Mulheres no topo: as contadoras paranaenses estão rompendo o glass Ceiling?. Advances in Scientific \& Applied Accounting, v. 8, n. 2, p. 244-270, 2015.

SOUZA, L. R.; NETO, E. L. G. R.; QUEIROZ, B. L. Maternidade e trabalho: o efeito do primeiro, segundo e terceiro (ou mais) filhos sobre a participação da mulher no mercado laboral. In: NOME DO CONBRESSO, n., 2016. Cidade. Anais... Cidade: Instituição, 2016, p. 1-44.

SZAPIRO, A. M.; FÉRES-CARNEIRO, T. Construções do feminino pós-anos sessenta: o caso da maternidade como produção independente. Psicologia: Reflexão e Crítica, v. 15, n. 1, p. 179-188, 2002.

WHEATLEY, D. Work-life balance, travel-to-work, and the dual career household. Personnel Review, v. 41, n. 6, p. 813-831, 2012. 


\section{DADOS DOS AUTORES}

\section{VIVIANE CORDEIRO DE ALMEIDA viviane@vmcontabil.com}

Doutoranda em Administração com foco em Pessoas, Trabalho e Sociedade pela PUC/MG

Instituição de vinculação: Pontifícia Universidade Católica de Minas Gerais

Belo Horizonte/ MG - Brasil

Áreas de interesse em pesquisa: Administração, Organizações, Mulher, Gênero.

^Av. Itaú, 525 Dom Cabral Belo Horizonte/MG 30535-012

\section{CAROLINA MARIA MOTA SANTOS cmmotasantos@gmail.com} Doutora em Administração com foco em Pessoas, Trabalho e Sociedade pela PUC/MG

Instituição de vinculação: Pontifícia Universidade Católica de Minas Gerais Belo Horizonte/ MG - Brasil

Áreas de interesse em pesquisa: Gestão de Pessoas, equilíbrio entre carreira e vida privada, liderança e gênero, estresse e qualidade de vida no trabalho. 